\title{
Internet-Intermediäre und virtuelle Plattformen medienökonomisch betrachtet
}

\author{
Hochschule für Angewandte Wissenschaften Hamburg (HAW), \\ Fakultät Design, Medien und Information
}

\section{Oktober 2021}

Der Special Issue der MedienWirtschaft veröffentlicht ausgewählte Beiträge, die auf der Jahrestagung der Fachgruppe Medienökonomie am 1. Oktober 2021 präsentiert wurden. Die Tagung fand an der Hochschule für Angewandte Wissenschaften Hamburg, Fakultät Design, Medien und Information, zu dem Thema "Internet-Intermediäre und virtuelle Plattformen medienökonomisch betrachtet" statt. Sie hatte das Ziel, eine Bestandsaufnahme und Zusammenführung des ökonomischen Wissens und wissenschaftlichen Forschungsstandes zu den Internet-Intermediären sowie zu den virtuellen Plattformen des Internets zu liefern, dabei aber den Fokus auf die für die Medienökonomie besonders relevanten Entwicklungen zu legen.

Auf der Tagung wurden 22 Vorträge gehalten. Im Vorfeld wurden 60 Reviews von 19 Gutachter:innen durchgeführt. Im Ergebnis hat die Tagung zu einem interessanten Einblick in die medienökonomischen Forschungen und Perspektiven geführt. Sie zeigt aber auch die vorhandenen Forschungslücken. Auf der Tagung diskutierten die Teilnehmer:innen mehrere Präsentationen und aktuelle Studien zu den vielfältigen wirtschaftlichen Konsequenzen der Entwicklungen im Bereich der Video-on-Demand-Dienste. Darüber hinaus standen die Folgen der Digitalen Transformation für die Medienorganisationen im Mittelpunkt. Behandelt wurden z. B. Aspekte wie organisationales und lebenslanges Lernen, aber auch spezifische Fragen des Content Managements, des Marketings, des Vertriebs und der Online-Werbung. Viele Präsentationen bezogen sich auf Aspekte der Produktpolitik wie z. B. auf Personalisierung, Paid Content, Datenökonomie, regionale Dienste und journalistische Leistungen. Außerdem wurden kritische Politikthemen behandelt und die europäische Regulierungsperspektive auf die Internet-Intermediäre und Plattformen vorgestellt.
Aufgrund des corona-bedingten Ausfalls der Tagung im letzten Jahr wurden zwei Nachwuchspreise vergeben: für das Jahr 2020 an Verena Telkmann von der TH Köln für den Beitrag „Broadcasters' content distribution and programming decisions in multi-channel environments: a literature review", der im Journal of Media Business Studies veröffentlicht wurde.

Der Nachwuchspreis für das Jahr 2021 ging an Jonas Weber (TU IImenau) für seinen in der MedienWirtschaft gemeinsam mit Jonas Steffl und Christopher Buschow veröffentlichten Beitrag „Plattformen für digitalen Journalismus in Deutschland. Eine Bestandsaufnahme und Typologie der Angebote am Markt".

Mit dem Best Paper Award der Tagung ausgezeichnet wurde der Beitrag „Location-Based Services als medienökonomische Erfolgsfaktoren für partizipative Nutzererfahrungen (in regionalen Nachrichtenmedien)" vom Autor:innenteam Per Ole Uphaus, Naomi Nowak, Björn Beringer und Harald Rau.

Die vorliegende Auswahl an Beiträgen für das Special Issue der MedienWirtschaft gibt einen Einblick in die Vielfalt der Perspektiven, die das Tagungsthema eröffnet hat.

Prof. Dr. Hardy Gundlach, HAW Hamburg 


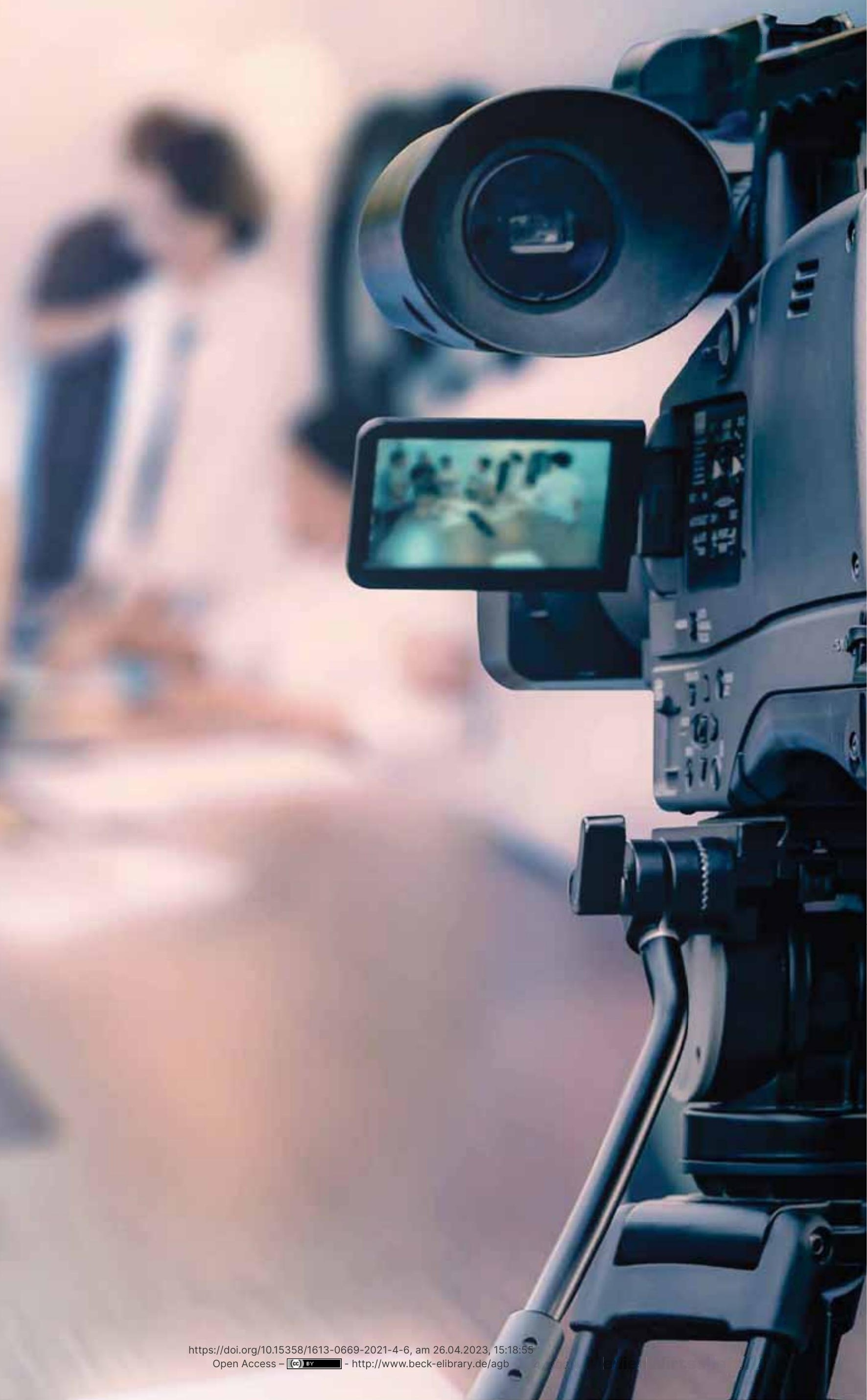

